\title{
Repensando a formação da nutrição para atenção básica à saúde a partir da percepção dos discentes de três instituições de ensino de Maceió/AL.
}

\author{
Rethinking the formation of nutrition for primary health care from \\ the perception of the students of three education institutions of \\ Maceió / AL.
}

Amanda Maria Monteiro Ferreira ${ }^{1}$

Kerle Dayana Tavares de Lucena ${ }^{2}$ Paulo José Medeiros de Souza Costa ${ }^{3}$

\section{Resumo}

A formação do nutricionista como profissional de saúde deve favorecer um processo de ensino-aprendizagem capaz de oferecer ao mercado de trabalho profissionais que, além da competência técnica, sejam aptos para compreender, analisar e intervir nos problemas sociossanitários dos cenários onde atuam. Este estudo tem como objetivo compreender a percepção dos discentes de nutrição acerca da formação para a Atenção Básica (AB). Tratase de uma pesquisa do tipo descritiva, exploratória, com abordagem qualitativa, realizada com discentes dos cursos de graduação em nutrição de três instituições de ensino superior do município de Maceió/AL. Utilizou-se o Grupo Focal como instrumento de produção do material empírico e a técnica

\footnotetext{
1 Mestranda em Ensino na Saúde e Tecnologia da Universidade Estadual de Ciências da Saúde de Alagoas Especialista em Saúde da Família pelo Programa de Residência Multiprofissional da Universidade Estadual de Ciências da Saúde de Alagoas.

${ }^{2}$ Docente do programa de mestrado em Ensino na Saúde e Tecnologia da Universidade Estadual de Ciências da Saúde de Alagoas. Docente efetiva da Universidade Estadual de Ciências da Saúde de Alagoas, Líder do Grupo de Pesquisa Saúde e Comunidade: buscando a integralidade do cuidado(GPESC); Professora da Faculdade de Medicina Nova Esperança (FAMENE) e Professora visitante no Programa de Pós-Graduação em Modelos de Decisão e Saúde da UFPB.

${ }^{3}$ Docente do programa de mestrado em Ensino na Saúde e Tecnologia da Universidade Estadual de Ciências da Saúde de Alagoas. Professor Adjunto do Núcleo de Saúde Materno-Infantil e do Adolescente do Centro de Ciências da Saúde da Universidade Estadual de Ciências da Saúde de Alagoas (UNCISAL),
}

Interfaces da Educ., Paranaiba, v.11, n.31, p. 440 - 473, 2020

ISSN 2177-7691 
de análise do conteúdo na modalidade de análise temática. Os discentes citaram a metodologia tradicional como o método de ensino mais utilizado, cujas atividades teóricas se sobrepuseram às práticas, que foram pontuais e fragmentadas. Mencionam, ainda, o Estagio Curricular Supervisionado (ECS) como sendo espaços privilegiado para a formação, bem como uma experiência crucial, única e enriquecedora no processo de ensino-aprendizagem do nutricionista para atuar no contexto da AB. Novas pesquisas, bem como o compartilhamento de experiências exitosas que abordem a formação do nutricionista para atuar no contexto da saúde pública e/ou $A B$, devem ser incentivadas, por possibilitar o avanço das discussões da atuação do nutricionista no âmbito do SUS e atenção básica.

Palavras-chave: Nutrição em Saúde Pública. Atenção Primária a Saúde. Formação profissional.

\section{Abstract}

The training of the nutritionist as a health professional should favor a teaching and learning process able of offering the labor market professionals who, besides their technical competence, are capable to understand, analyze and intervene in the social and health problems of the realities and places where they work. This study aims to understand the perception of nutrition students about training for Primary Health Care. This is a descriptive, exploratory research with a qualitative approach, carried out with undergraduate nutrition students from three higher education institutions in the city of Maceió / AL. The Focal Group was used as an instrument to produce empirical material and the content analysis technique was used as a thematic analysis modality. The students cited the traditional methodology as the most used teaching method, so that the theoretical activities overcame the practices, which were punctual and fragmented. They also mentioned the Supervised Internship as being a crucial, unique and enriching experience in the process of training the nutritionist to work in the context of Primary Health Care. Both new academic research and the sharing of successful experiences that talk about the training of nutritionists to work in the context of public health and Interfaces da Educ., Paranaíba, v.11, n.31, p. 440 - 473, 2020 
/ or Primary Health Care should be encouraged, as they enable the advancement of discussions of nutritionist activities in the Unified Health System (SUS) and Primary Health Care (PHC).

Keywords: Public Health Nutrition. Primary Health Care. Professional qualification.

\section{Introdução}

Tem sido um grande desafio formar profissionais com perfil adequado às necessidades sociais, além da capacidade técnica, uma vez que implica propiciar aos discentes a capacidade de aprender a aprender, de trabalhar em equipe, de comunicar-se, de ter agilidade frente às situações e de ter capacidade propositiva - características gerais imprescindíveis ao profissional graduado, que difere da formação tradicional, sendo oportuno repensar a formação a partir das Instituições de Ensino Superior (IES) (SCHOTT, 2018).

Nos últimos 30 anos, o Brasil sofreu diversas mutações que o transformaram em um país emergente, trazendo novos desafios ao Sistema Único de Saúde (SUS) e para os profissionais que nele atuam, tornando-se primordial ponderar as mudanças no cenário de morbimortalidade do país nas últimas décadas (ALVES, 2017).

Uma delas é a transição demográfica, que evidencia o envelhecimento da população de maneira crescente. As projeções sugerem que a proporção da população com mais de 65 anos aumentará cerca de sete vezes entre 1950 e 2050, com a adição de cerca de 51 milhões de pessoas, das quais prováveis 16 milhões terão mais de 80 anos, aumentando a expectativa de vida. Tratase de um ritmo de envelhecimento três vezes mais rápido que o observado em países como o Reino Unido, França e Suécia, cuja transição demográfica iniciou-se muitas décadas antes da brasileira. (ALVES, 2017).

Outra modificação importante que vem afetando a população brasileira é a transição epidemiológica, que se estabelece a partir de transformações importantes no perfil de morbimortalidade, sendo excitada por determinantes demográficos, econômicos e sociais, em que as causas de mortes por doenças 
infectocontagiosas foram enfraquecendo, enquanto as Doenças Crônicas Não Transmissiveis (DCNT) foram aumentando gradualmente (ARAÚJO, 2012).

Paralelamente à transição demográfica e à transição epidemiológica, outras modificações que têm afetado a população brasileira abarcam os aspectos nutricionais, sendo alvos de reflexões para a formação dos cursos da saúde e, em especial, para o curso de nutrição. Essas modificações são ocasionadas por alterações no perfil nutricional em resposta às mudanças no padrão de comportamento alimentar e da redução na prática de atividades físicas da população, conhecida como transição nutricional (BATISTA FILHO; RISSIN, 2003; SOUZA, 2010).

A transição nutricional trouxe mudanças consideráveis para o perfil de saúde da população brasileira devido ao aumento das prevalências do sobrepeso e da obesidade como os principais legados desta transição, marcados também pela diminuição de deficiências nutricionais e desnutrição (SOUZA, 2010).

Desta forma, a complexidade dos problemas alimentares, demográficos e epidemiológicos impõe reformulações na formação dos profissionais de saúde, inclusive do nutricionista, com táticas de fortalecimento do conteúdo de saúde pública nos currículos dos cursos de nutrição e da saúde como estratégia essencial (SCHOTT, 2018).

Diversos estudos apontam a importância de o nutricionista integrar os recursos humanos para a $\mathrm{AB}$, tendo em vista que sua ausência pode resultar em execução superficial das ações relacionadas à alimentação e à nutrição. Esta área vem se destacando como fundamental para a promoção de saúde dos principais agravos que foram apresentados anteriormente envolvendo a transição demográfica, epidemiológica e nutricional (TEIXEIRA; SILVA, 2017).

Entretanto, apesar de ser clara a importância da inserção do nutricionista no contexto da atenção básica, esses possuem pouca experiência profissional, sentem-se pouco preparados para atuar em saúde da família e apresentam dificuldades de compreensão da realidade social, pois a formação acadêmica não proporcionou segurança para atuação na área (AGUIAR; COSTA, 2015). 
Neste sentido, refletir acerca da formação do nutricionista na AB, promove, além da contextualização teórica acerca deste tema, o fortalecimento de subsídios para as IES que ofertam o curso de nutrição do Brasil, tanto para a apresentação de proposta de Projetos Políticos Pedagógicos mais críticos, quanto para a elaboração de currículos que propiciem aos discentes o preparo necessário para atuar no contexto da $\mathrm{AB}$. Com esse propósito, este estudo teve como objetivo compreender a percepção dos discentes de nutrição acerca da formação para Atenção Básica.

\section{Referencial teórico}

A história dos cursos de Nutrição no Brasil e na América Latina remetese à fundação do Instituto Nacional de Nutrição e da Escola de Dietistas, em 1933, em Buenos Aires, pelo médico argentino Pedro Escudero, pioneiro do campo da Nutrição na América Latina. No Brasil, o primeiro Curso de dietistas foi instituído em 1939 pelo Decreto Estadual no 10.617 de 24/10/1939, por iniciativa de médicos nutrólogos, como cursos técnicos de nível médio e a duração do curso era de apenas um ano (YPIRANGA; GIL, 1989). Posteriormente, os cursos de dietistas passaram a ter de dois a três anos para formação. Apenas em 1972 o curso de Nutrição passou a ser de graduação e ter quatro anos de duração (VASCONCELOS, 2002).

No tempo de sua construção, havia duas correntes de saber científico em disputa pelo campo da Nutrição. A primeira, biológica, focava o consumo de alimentos e a utilização biológica dos nutrientes, sendo intensamente influenciada pelas escolas norte-americanas e europeias de Nutrição, as quais contribuíram para a formação dos campos da nutrição básica, experimental e clínica. Já a segunda corrente ressaltava os aspectos relacionados à produção agrícola, à distribuição e ao consumo alimentar das populações, influenciada pela abordagem original de Pedro Escudero. Esta última vertente foi a essência da nutrição social, com atuação voltada para o coletivo e para os aspectos econômicos do processo alimentar. Essa perspectiva contribuiu para a origem da área, tanto de alimentação coletiva ou institucional, quanto de nutrição em saúde pública.(RECINE et al, 2012). 
A abertura de novos cursos de Nutrição se deu, sobretudo, a partir de 1976, após a instituição do II Programa Nacional de Alimentação e Nutrição, que teve como uma das principais diretrizes instigar o desenvolvimento e a capacitação de recursos humanos em Nutrição (YPIRANGA; GIL, 1989). A partir desse momento, notou-se um rápido processo de criação de novos cursos no país, com aumento expressivo do número de vagas nesses cursos. Até 1981, já havia 30 cursos de Nutrição no Brasil (VASCONCELOS, 2002; YPIRANGA; GIL, 1989).

Recentemente, no que tange ao número de cursos de graduação em Nutrição, através de uma consulta à plataforma eletrônica do Ministério da Educação (e-MEC), foi revelada a existência de 561 cursos presenciais de bacharelado em Nutrição, além de mais 12 cursos de bacharelado à distância, o que gera um total de 576 cursos de Nutrição credenciados no país no ano de 2017. Desses, apenas 67 cursos estão em instituições públicas (ensino gratuito), representando apenas $12 \%$ dos cursos presenciais. A grande maioria dos cursos de graduação em Nutrição no país está na esfera privada (total de 494), incluindo os cursos à distância, pertencendo todos à esfera privada. Já no ano de 2019, estão registrados no Ministério da Educação (MEC), em atividade, 632 cursos de bacharelado em Nutrição (BRASIL, 2017; BRASIL, 2019, ALVES, 2018).

Desde a instituição e a adesão das Diretrizes Curriculares Nacionais $(\mathrm{DCN})$ às IES, foi afiançada maior flexibilidade de atuação, permitindo autonomia, em que os currículos propostos pudessem construir perfis acadêmicos e profissionais com competências, habilidades e conteúdos condizentes com uma abordagem contemporânea de formação (RECINE et al, 2012).

De acordo com as Diretrizes Curriculares dos cursos de Nutrição, estabelecidas em 2001,

O profissional nutricionista deve ter uma formação generalista, humanista e crítica, capacitado a atuar, visando à segurança alimentar e à atenção dietética, em todas as áreas do conhecimento em que a alimentação e nutrição se apresentem fundamentais para a promoção, manutenção e recuperação da saúde e para a prevenção de doenças de indivíduos ou grupos populacionais, contribuindo para a 
melhoria da qualidade de vida, pautado em princípios éticos, com reflexão sobre a realidade econômica, política, social e cultural" (BRASIL, 2001).

A formação do nutricionista deve favorecer também um processo de ensino e aprendizagem capaz de ofertar no mercado de trabalho profissionais que, além da competência técnica, estejam aptos para compreender, analisar e intervir nos problemas sociossanitários dos locais e cenários onde atuam (JUNQUEIRA; COTTA, 2014).

Para atuação na saúde pública, mais precisamente na saúde da família, o nutricionista necessita dispor, conforme citado, de uma formação para além da sua capacidade técnica, sendo voltado para as questões sociais, com uma capacidade de leitura e resolução dos principais problemas de saúde, de acordo com a realidade socioeconômica e cultural, em todo raio de abrangência da comunidade a qual será inserido (JUNQUEIRA; COTTA, 2014).

$\mathrm{Na}$ busca por favorecer esta formação dos estudantes com visão ampliada de saúde, ativos e comprometidos com a transformação da realidade, considerando a complexidade que o caracteriza, faz-se necessário também introduzir novas formas de organizar e produzir o conhecimento, até então representado pela disciplinaridade e fragmentação do objeto. Dentro das novas tendências, a introdução de metodologias ativas de aprendizado junto à diversificação de cenários de práticas ao longo de todo processo de ensinoaprendizagem são questões centrais para alterar a estrutura dos currículos atuais, centrando-se na pedagogia interativa, critica e reflexiva. O ensino na graduação em nutrição deve inserir no seu processo de ensino-aprendizagem os novos métodos de ensino, porém essa ainda não é uma prática cotidiana na maioria das Instituições de Ensino (PINHEIRO et al.,2012; BOGANHA, 2016).

Nesse contexto, é ventilado em alguns estudos a importância do processo de formação e atuação do nutricionista no contexto da atenção básica, Cunha; Rodrigues (2016, p. 26) afirmaram em seu trabalho que "a vivência dos discentes de nutrição no contexto da Atenção Básica é essencial para compreender a relevância do papel e da atuação profissional do nutricionista inserido nas equipes de $A B$ ", devendo ser fortalecida durante a Interfaces da Educ., Paranaíba, v.11, n.31, p. 440 - 473, 2020 
graduação, protegendo o fortalecimento e o aprimoramento do processo de ensino-aprendizagem neste contexto.

\section{Método}

Este estudo é parte da dissertação de mestrado intitulada: "Percepção dos discentes de nutrição acerca do processo de formação para a Atenção Básica", entregue ao corpo docente do programa de Mestrado Profissional em Ensino na Saúde de Tecnologia da Universidade Estadual de Ciências da Saúde de Alagoas. Trata-se de uma pesquisa do tipo descritiva, exploratória, com abordagem qualitativa. Optou-se pela abordagem qualitativa por permitir a compreensão de valores culturais e representações de determinado grupo acerca de um tema específico, sob diferentes perspectivas, abordando as relações entre atores sociais e ações implementadas através da percepção, a intuição e a subjetividade. Ademais, tem como característica a empiria e a construção gradativa do conhecimento até a compreensão da lógica interna do objeto estudado (MINAYO, 2014).

O estudo foi realizado em três universidades do município de Maceió/AL, sendo duas públicas e uma privada. Os sujeitos da pesquisa totalizaram 30 (trinta) discentes do curso de nutrição das universidades, cenários do estudo, sendo realizado três grupos focais, com a participação em média de 10 (dez) alunos por grupo focal de cada instituição.

Foram incluídos acadêmicos que estavam cursando o último ano do curso de graduação em nutrição das três instituições de ensino superior de Maceió/AL, que possuíam turmas concluintes.

Foram excluídos aqueles acadêmicos que não estavam devidamente matriculados, os desperiodizados, os alunos afastados por férias, por doenças ou por qualquer outro motivo que impedia sua participação durante a pesquisa, e os transferidos de outras Instituições de Ensino e que iniciaram e não estavam concluindo na mesma matriz curricular.

Para produção das informações foi utilizado o Grupo Focal (GF), que teve como objetivo emergir as percepções das turmas acerca do processo de formação em nutrição para atuação na $\mathrm{AB}$ na IES que estavam inseridos, guiado por um roteiro contendo questões disparadoras sobre o tema da Interfaces da Educ., Paranaíba, v.11, n.31, p. 440 - 473, 2020 
investigação: O que vocês entendem por atenção básica à saúde?; De que forma foi abordada a atenção básica a saúde na formação de vocês?; Como aconteceu o processo de ensino-aprendizagem nesta área?; Foi estimulada a atuação profissional como nutricionista na atenção básica? (Vocês se sentem atraídos para atuarem na atenção básica? Por qual motivo? Vocês se sentem aptos para atuar na atenção básica? Por qual motivo?; Quais as sugestões referentes ao processo de formação da nutrição para atenção básica vocês deixariam para os docentes e/ou IES?

O GF se constitui em um tipo de entrevista ou conversa em grupos pequenos e homogêneos. Para serem bem sucedidos, precisam ser planejados, pois visam obter informações, aprofundando a interação entre os participantes, seja por gerar consenso, seja para explicitar divergências. A técnica deve ser aplicada mediante um roteiro que vai do geral ao especifico, em ambiente não diretivo, sob a coordenação de um moderador capaz de conseguir a participação e o ponto de vista de cada um. O valor principal dessa técnica fundamenta-se na capacidade humana de formar opiniões e atitudes na interação com ouros individuos (MINAYO, 2014).

Os procedimentos para produção das informações ocorreram em seis etapas: 1) visita aos campos de pesquisa; 2) articulação com os professores responsáveis das disciplinas de nutrição em Saúde Pública para agendamento da produção das informações do material empírico (data, hora e local); 3) elaboração do calendário com as respectivas datas das atividades; 4) reunião com os pesquisadores; 5) produção do material empírico estudo e 6) armazenamento das produções (gravações).

A técnica de análise do material empírico produzido foi a de conteúdo na modalidade de análise temática. Segundo Bardin (2011), a análise de conteúdo pode ser definida como:

\footnotetext{
Um conjunto de técnicas de análise de comunicação visando obter, por procedimentos sistemáticos e objetivos de descrição do conteúdo das mensagens, indicadores (quantitativos ou não) que permitam a inferência de conhecimentos relativos as condições de produção/recepção dessas mensagens (BARDIN, 2011, p.42).
} 
Os aspectos éticos da pesquisa atenderam aos principios éticos e científicos propostos na resolução 466 de 12 de dezembro de 2012 do Ministério da Saúde do Conselho Nacional de Saúde (CNS). Foram garantidos aos participantes da pesquisa o sigilo, anonimato e o direito de desistir da pesquisa.

O projeto foi submetido ao CEP da UNCISAL, respeitando a resolução 466/12 do CNS, por meio da Plataforma Brasil, em 25.04.2018, sendo aprovado em 23/05/2018 sob o número de Certificado de Apresentação para Apreciação Ética CAAE: 85922718.8.0000.5011.

\section{Resultado e discussão}

A percepção dos discentes apresenta os depoimentos envolvendo o processo de ensino-aprendizagem em nutrição para a AB da IES estudadas. Desdobraram-se em 4 categorias: 1. Métodos de ensino-aprendizagem utilizados pelas IES na formação dos discentes no contexto da AB; 2 . Desequilíbrio na relação teoria e prática; 3. Ações pontuais e a fragmentação do processo ensino-aprendizagem; 4. O estágio supervisionado e sua intersecção com a formação da nutrição para a AB.

\section{Métodos de ensino-aprendizagem utilizados pelas IES na formação dos discentes no contexto da $\mathbf{A B}$.}

Os depoimentos dos discentes apresentam compreensões acerca dos métodos de ensino-aprendizagem utilizados durante as disciplinas de nutrição que envolvia a temática de $\mathrm{AB}$ como aulas pouco motivadoras, envolvendo a transmissão de conteúdo (educação bancária e tradicional), demonstrando uma aprendizagem não significativa, conforma apresentado a seguir:

GF02: "As nossas disciplinas eram só teoria mesmo, bem tradicional". GF03: "São muitas leis, programas, cadernos e ficava meio cansativo... aquelas aulas sempre do mesmo jeito, o professor falando e a gente escutando, na maioria das vezes com slide". 
GF3: "E principalmente nas aulas de saúde pública, as aulas são muito" chatas, os professores deveriam se reciclar um pouquinho mais em relação a isso, aos métodos de ensino, para serem umas aulas mais atrativas e mais dinâmicas. Porque ninguém merece! É falando do início ao fim, e você tá dormindo no final ne?".

Os modelos de ensino tradicionais induzem os discentes a uma postura quase sempre passiva, ou seja, sem a oportunidade de evidenciar suas opiniões, interesses e de repassar seus saberes também para o docente, através de uma comunicação mútua, com via de mão dupla. Já as metodologias ativas procuram desenvolver o aprendizado, aproveitando parâmetros reais ou simulados, construindo processos interativos de conhecimento, de análise ou de pesquisa.

Apoiando com o que foi apresentado pelos relatos acima dos discentes deste estudo, Escobar (2013) avaliou as estratégias de ensino-aprendizagem utilizadas pelos professores na Graduação em Nutrição de uma Universidade no Paraná, o que apresentou predominância de aulas expositiva, e não de expositiva dialogada, sugerindo assim que o foco do professor não está voltado para a aprendizagem do aluno, e, sim, para a transmissão do conhecimento. Assim, pode-se destacar que, na percepção dos graduandos avaliados, as estratégias de ensino influenciam a sua aprendizagem e necessitam ser repensadas.

No Brasil, a maioria dos cursos de graduação da área da saúde, assim como o curso de nutrição, apresentam currículos amparados na metodologia tradicional de ensino, combinados por disciplinas diversificadas que contemplam temas de formação básica, técnica e clinica, oferecidas de modo semestral ou anual (GARCIA et al., 2007).

Berbel (2011, p. 54) enfatiza que "para a elaboração de novas propostas pedagógicas, os cursos de graduação e com destaque os da área da saúde, têm sido estimulados a incluírem, metodologias de ensino que permitam dar conta dos novos perfis delineados para os seus profissionais". Além disso, a distribuição dos conteúdos específicos em disciplinas isoladas e a ausência de atividades inter e transdisciplinares atrapalham a aprendizagem e a motivação dos alunos, que comumente não compreendem a afinidade entre os conteúdos 
abordados na teoria e o exercício da profissão, principalmente nos primeiros anos do curso (GARCIA et al., 2007).

Quando as disciplinas interagem entre si causam relações que tendem a ser convergentes, cooperando para a motivação e para a aprendizagem do aluno (ALMEIDA FILHO, 2005). Em um estudo sobre o processo de ensino para formação de médicos na AB, Garcia et al. (2007) conclui que interdisciplinaridade é uma exigência para a integralidade e, neste sentido, as instituições de ensino superior têm debatido novos currículos em cursos da saúde, valorizando a interdisciplinaridade e, ainda, as novas metodologias de ensino, a exemplo das metodologias ativas.

Pinheiro et al. (2012) estabelece que a introdução de metodologias ativas unida à interdisciplinaridade e a diversificação de cenários de práticas ao longo de todo processo de ensino-aprendizagem são questões fundamentais para alterar a estrutura dos currículos atuais.

De acordo com Sobral e Campos (2012, p. 209):

\begin{abstract}
A metodologia ativa (MA) é uma concepção educativa que estimula processos de ensino-aprendizagem crítico-reflexivos, no qual o educando participa e se compromete com seu aprendizado. O método propõe a elaboração de situações de ensino que promovam uma aproximação crítica do aluno com a realidade; a reflexão sobre problemas que geram curiosidade e desafio; a disponibilização de recursos para pesquisar problemas e soluções; a identificação e organização das soluções hipotéticas mais adequadas à situação e à aplicação dessas soluções.
\end{abstract}

São diversas as estratégias que podem ser utilizadas no ensinoaprendizagem como: aula expositiva; aula expositiva dialogada; estudo de texto, portfólio; tempestade cerebral; mapa conceitual; solução de problemas; estudo dirigido; dramatização; seminário; estudo de caso; palestras e entrevistas; discussão e debates; laboratórios e oficinas; ensino com pesquisa; lista de discussão por meios informatizados; grupo de verbalização e de observação $(\mathrm{GO} / \mathrm{GV})$. Apesar do grande número de estratégias, muitos professores as desconhecem, não sabem como utilizá-las ou não são motivados a incluí-las durante suas aulas (BORGES; ALENCAR, 2014).

Recentemente, Gordiano (2018) considerando o processo histórico de inserção das metodologias ativas na área de saúde e em especial o uso do PBL Interfaces da Educ., Paranaíba, v.11, n.31, p. 440 - 473, 2020 
no ensino da saúde, desenvolveu uma revisão integrativa com o objetivo de verificar se na área de nutrição a aplicação do PBL tem proporcionado melhor desempenho aos alunos, se comparada a técnica tradicional de ensino. A análise dos artigos apontou que os acadêmicos apresentaram melhor desempenho quando aplicadas metodologias ativas. Foi também apontada a necessidade de métodos diferenciados de avaliação para a adaptação da aplicação destas metodologias.

Ainda nesse contexto, as metodologias ativas também incluem a problematização como tática de ensino/aprendizagem, com o objetivo de alcançar e motivar o discente, pois diante do problema, ele se detém, examina, reflete, relaciona com a sua história e ressignifica suas descobertas. Aprender por meio da problematização e/ou da resolução de problemas de sua área é uma das possibilidades de envolvimento ativo dos alunos em seu próprio processo de formação (MITRE et al., 2008).

Em uma das IES estudada os discentes apontaram que nas aulas de nutrição e saúde pública utilizavam-se métodos de ensino-aprendizagem baseado em metodologias ativas de ensino:

GF 01: "As aulas são dialogadas, expositivas também, além das discussões de caso, dinâmicas e seminários... a gente consegue interagir, discutir, solucionar'. Então assim, foi interessante, porque não era só teoria, era prática discutida na teoria".

O uso de metodologias ativas interdisciplinares na formação de profissionais da área da saúde pode ocasionar avanços no que se alude a motivação e à percepção de aprendizagem, quando confrontadas com a aula expositiva tradicional e acredita-se que tais estratégias podem ser utilizadas de maneira segura nos currículos de cursos da saúde, gerando a interação entre conteúdos formativos e a prática profissional e instigando a formação de indivíduos proativos, que apresentam uma visão generalista, critica e reflexiva (SANTOS et al., 2017).

Além das metodologias ativas, podemos citar o ensino Híbrido, o termo Híbrido vem de cruzamento, combinação, convergência. É uma associação de duas coisas que podem ser diferentes e se complementam. Quando pensamos 
do ensino unindo educação, atualmente, com a popularidade dos meios digitais e da informática, temos que falar de tecnologia, fincando cada vez mais fácil contar com essa alternativa, sendo a ideia principal, nesse caso, levar o meio online para a sala de aula (CHRISTENSEN; HORN; STAKER, 2013).

Nos deparamos a explicação de que o ensino híbrido une dois ou mais modelos para explorar ao máximo as capacidades e o potencial dos alunos, além de conservar o interesse do mesmo, seja na própria escola, no laboratório, em casa ou qualquer ambiente similar, podendo ser implementado por docentes, escolas e IES, tanto as mais carentes como as que possuem uma estrutura tecnológica sofisticada (CHRISTENSEN; HORN; STAKER, 2013).

Ainda no contexto de metodologias ativas de ensino, vale mencionar também o modelo de sala de aula invertida, podendo ser apresentada como estratégia de mudanças em relação ao modelo tradicional de ensino. Como o próprio nome já diz, existe uma inversão no processo de ensino e aprendizagem que estimula o aluno a buscar e demonstrar conhecimento, desestimulando o hábito do professor em executar seu papel de detentor do conhecimento, levando a uma condição mais de mediador em sala de aula (SOUZA; CALABAIDE, ERNESTO, 2018).

O aluno, historicamente é acostumado a uma condição mais passiva no processo do conhecimento, cujo papel era o de absorver as informações, torna-se mais ativo, com responsabilidades no processo de construção de conhecimento. Trata-se, portanto, de um modelo de ensino que coloca, de fato, o discente como protagonista, aproximando-o dos temas e conteúdo antes mesmo de a aula começar. A sala de aula invertida é um dos modelos mais interessantes de ensinar, pois retém no ambiente virtual o que é informação básica do conteúdo a ser aprendido, atribuindo atividades mais criativas e supervisionadas para a sala de aula (MENDES, 2016; OLIVEIRA, 2015)

Contudo, como podemos inverter o modelo formal de aula? Por meio dos recursos digitais, por exemplo, de modo que os alunos possam acessar vídeos, textos, reportagens e materiais básicos a respeito de conteúdos que serão abordados em sala aula, estudando-os e fazendo uma leitura crítica/ reflexiva 
e posteriormente levar para discussão em sala de aula para os colegas e professores (MORAN, 2015; SOUZA; CALABAIDE, ERNESTO, 2018).

As metodologias ativas são pontos primitivos para prosseguir para processos mais avançados de reflexão, integração cognitiva, de intelectualização e de reestruturação de novas práticas pedagógicas. Estas consistem seguindo quatro princípios: 1 .autonomia do estudante; 2 . contexto de aprendizado; 3. trabalho em equipe; 4. princípio de aprendizagem de adultos. As metodologias de aprendizagem precisam acompanhar os objetivos pretendidos das atividades acadêmicas pré-definidas (MORAN, 2015; SOUZA; CALABAIDE, ERNESTO, 2018)

Se desejarmos que os alunos sejam proativos, precisamos eleger metodologias ativas em que os alunos se envolvam em atividades com níveis mais altos de exigência; que envolvam a tomada de decisões e avaliação de resultados, com apoio de materiais relevantes para o aprendizado, sendo planejados previamente (MORAN,2015; SOUZA; CALABAIDE, ERNESTO, 2018).

Além do mais, a aprendizagem parece tornar-se mais efetiva quando o conteúdo contempla o cotidiano dos estudantes, sendo basilar considerar o conhecimento que os mesmos já possuem, procedentes de sua vivência e realidade (FUJITA, et al, 2016).

\section{Desequilíbrios na relação teoria e prática.}

Os depoimentos dos discentes conjeturam que os conteúdos teóricos de nutrição acerca da $\mathrm{AB}$ se sobrepuseram em detrimento da prática como pode ser observado abaixo:

GF 1: "Eu acho assim, que nem todo mundo tem essa afinidade com as politicas. Então eu acho que, claro, a gente tem que ver as politicas todo aquele contexto, mas trazendo de um modo mais objetivo, mais prático, não só preso na teoria como foi, deveria ter mais atividades práticas ".

GF2: "Acho que pode ter faltado mais ter pratica".

GF3: "Por que assim, é uma carga horaria alta das disciplinas, algumas são 60 horas e outras são 80h, mas que os professores, os docentes, as vezes se prende muito a teoria. Acho que se dividisse melhor a teoria $e$ a pratica, acho que seria bem melhor para o aluno, então se torna uma disciplina cansativa!".

GF3: "Eles poderiam dividir melhor esse tempo. Que a teoria ela é importante mas a pratica também, é muita teoria. Então eles poderiam Interfaces da Educ., Paranaíba, v.11, n.31, p. 440 - 473, 2020 
Repensando a formação da nutrição...

dividir. Que nem é feito na clínica. Um dia a teoria outro dia seria a pratica para a gente ter essa vivencia."

Existe uma dicotomia entre teoria e prática compreendida na maioria dos currículos da área da saúde, que norteia-se pela concepção de construção de conhecimento positivista, abrangendo a organização dos processos de ensino de "forma linear, do teórico para o prático e do ciclo básico para o profissionalizante”. Essa abordagem implica que os conteúdos precisem ser ministrados antecipadamente, a fim de que o estudante seja capaz de "dominar" a teoria e, então, aplicá-la na prática, não incorporando a prática como um espaço pedagógico de ensino e aprendizagem (SANTOS et al., 2005; PINHEIRO et 1.,2012)

Pinheiro et. al., (2012, p.23) em seu estudo ao analisar a percepção de discentes e profissionais com seu perfil de formação do nutricionista para saúde pública, os participantes destacaram o problema da linearidade do processo de ensino, que visa primeiro abordar aspectos teóricos, deixando a prática para o final do curso.

O conhecimento teórico sem a prática se torna vago, incerto e indefinido, exigindo uma complementação e a aplicabilidade dessa teoria através da prática. Esta, por sua vez propicia a experiência e desenvolve a consciência crítico- reflexiva sobre o fazer nos cursos da saúde, incluindo a nutrição (MAIS et al, 2015).

Neste sentido, Menezes, Santiago (2014, p. 23) marcam que "os conteúdos precisam ser problematizados em um processo dinâmico e dialógico com as situações da vida, na realidade concreta", com a finalidade de considerar de maneira critica essa realidade para assim identificar e compreender as diversas situações e formular soluções exequiveis.

Tal achado demonstra a acuidade e necessidade de vincular prática e teoria em um ininterrupto movimento dialético de ação-reflexão-ação, de agirrefletir-agir-transformar. É neste movimento que o saber é construído. Freire (1979, p. 8) enfatiza que a "ação e reflexão são constituintes inseparáveis da prática”. Defende, ainda, que o homem e o mundo estão interligados, não há 
este sem aquele, assim como "não pode haver reflexão e ação fora da relação" homem-realidade.

Em relação à formação em nutrição, Mais et al. (2015) recomenda que as disciplinas que fortalecem o entendimento da atuação do nutricionista em saúde coletiva (atenção básica, politicas e programas institucionais e vigilância sanitária) devem ser distribuídas ao longo dos cinco anos de integralização curricular.

Ainda nesse contexto, Reccine et al (2012) sugere que as atividades práticas estejam desde o início e ao longo do curso, permeando toda a formação do profissional, de forma integrada e multidisciplinar.

Como exemplo, a matriz curricular do Curso de Nutrição da UFSC (Das Neves; Souza e Vasconcelos, 2014) foi estruturada de forma que as disciplinas e seus respectivos conteúdos (ementas) respondam a um objeto integrador. $\mathrm{O}$ objeto integrador consiste em um tema problematizador que norteia as atividades práticas articuladas e discussões teóricas a cada ano/semestre do Curso. Destaca-se que o Curso não possui uma estrutura modular, mas, com base no tema problematizador, as disciplinas foram alocadas de forma a responder a uma lógica de verticalização de conhecimentos com base na complexidade da atenção em saúde.

Em relação as disciplinas voltadas para a $\mathrm{AB}$, merece destaque a identificação de apenas cinco cursos, no Brasil, que oferecem a disciplina Nutrição em Saúde da Família. Ponderando a relevância que os temas relacionados ao Sistema Único de Saúde necessitam ter na formação dos profissionais, e o papel da atenção básica em geral e à Estratégia Saúde da Familia (ESF) no SUS, a oferta dessa disciplina precisaria ser maior (Reccine et al, 2012).

Neste sentido, torna-se essencial proporcionar a aproximação entre a teoria e a prática, entre o ideal e o real, pois a partir da inserção na realidade é possivel refletir sobre os desafios encontrados e desenvolver a consciência crítica que é indagadora e dialógica (FREIRE, 1979; 2001). Uma formação que não propicia essa aproximação pode se tornar essencialmente teórica, comprometendo a atuação profissional pela insegurança de não ter vivenciado as situações reais (SOBRAL, 2018).

Interfaces da Educ., Paranaíba, v.11, n.31, p. 440 - 473, 2020 
Ressalta-se que, além da teoria e da prática referente às disciplinas comumente oferecidas, deve ser oportunizada aos estudantes a participação em atividades complementares, tais como: monitorias, estágios extracurriculares, programas de iniciação científica, programas de extensão, estudos complementares e cursos realizados em outras áreas afins (RECCINE et al.,2012). As vivências dessas práticas educativas ampliam a formação do estudante e institui experiência relevante, por agregar outros valores à formação profissional. Apesar disso, segundo o ENADE, em 2007, um número significativo de formandos de Nutrição $(51,6 \%)$ declarou não ter participado de nenhuma atividade acadêmica extraclasse durante a graduação (BRASIL, 2007).

\section{Atividades práticas pontuais e a fragmentação no processo ensino- aprendizagem}

Em uma das Universidades estudadas, os discentes relataram que tiveram algumas atividades práticas, porém bem pontuais e de forma fragmentada, que não permitiram entender o objetivo e condensar com os conteúdos ministrados em sala de aula, segundo exposto a seguir:

GF 3: "A gente tem algumas visitas as UBS" mas assim, acho que não é suficiente né? Porque assim, é uma coisa muito pontual, quebrada, só aquele atendimento ou orientação e pronto, a gente não chega a acompanhar, muitas vezes nem entendemos o objetivo".

GF3: "São rápidas bem rápidas as visitas. Uma visita de uma semana, duas semanas para fazer o desenvolvimento da aula teórica, mas de certa forma é rápida, pois a gente não consegue condensar o conteúdo da aula teórica com o que vivenciamos na pratica".

GF 3: "Sendo bem sincera, por mais que as professoras sejam muito engajadas, elas tentem, os assuntos, pelo menos com a minha experiência, eles ficam partidos, então a gente não consegue fazer essa união dos assuntos, como ela falou, a gente só conseguiu visualizar isso no estágio, por que o tempo é maior”.

A problemática encontrada a partir da análise dos depoimentos foi com relação à fragmentação no ensino-aprendizagem. As atividades práticas pontuais promovem uma formação repartida e, consequentemente, formaram profissionais que ofertem uma assistência igualmente fragmentada, na qual a ênfase será na doença, naquele problema específico de saúde, naquela parte 
específica do corpo humano, naquela demanda especifica pontual do serviço, o que ratifica semelhança ao modelo hospitalocêntrico, o qual não se preocupa em enxergar aquela pessoa de forma integral e holística.

A educação flexneriana, fragmentada, aquela em que o cuidado é centrado na doença, não é combinada com os atuais desafios, focalizada em realidades demográficas e epidemiológicas primitivas e despreocupada com a formação de profissionais capazes para enfrentar os reais e diferentes problemas de saúde contemporâneos (MENDES et al., 2016).

Os conteúdos dedicados pelos cursos não podem ser pedaços de uma realidade, desconectados da totalidade. Por isso, torna-se importante um currículo que apresente propostas para trabalhar com os estudantes "situações significativas de sua realidade cuja análise crítica permita reconhecer a interação de suas partes, e possam compreender a totalidade e os conteúdos ganhem significado” (MENEZES; SANTIAGO, 2014).

Diante disso, a proposta de Integração entre o Ensino, o Serviço e Comunidade (IESC) no processo de formação vem sendo enfatizada pelo Ministério da Saúde como uma estratégia importante para a formação de profissionais que atendam aos principios e diretrizes do Sistema Único de Saúde (SUS), favorecendo a práticas profissionais para responder às necessidades de saúde da população do trabalho na Atenção Básica (PINTO; FORMIGLI; RÊGO, 2007).

A aproximação de discentes com os serviços da Atenção Básica, desde as primeiras séries dos cursos, de maneira continua e articulada é indicada como um aspecto positivo da integração, sendo valorizada igualmente por estudantes, docentes e professores colaboradores e profissionais dos serviços (RECINE, 2012; RECINE, 2014 MARIN et al., 2014; BRASIL, 2018; SCHOTT, 2018; GORDIANO, 2018; LIMA et al., 2019).

Acrescentam-se também que a integração ensino-serviço contribui para um olhar abrangente do processo saúde/ doença, possibilita a construção coletiva do saber, para o conhecimento do trabalho em equipe e seu funcionamento e, ainda, das necessidades dos serviços de saúde; consolidação da relação teoria-prática, formação crítico-construtivista, oportunidade de desenvolver e aperfeiçoar habilidades de cuidado, educação, Interfaces da Educ., Paranaíba, v.11, n.31, p. 440 - 473, 2020 
gerência e pesquisa (MARIN et al., 2014; GORDIANO, 2018; LIMA et al., 2019; SANTOS; CAVALCANTE, 2019).

Salientam-se ainda avanços na compreensão a respeito da interdisciplinaridade e do funcionamento da rede de serviços de saúde, reconhecimento do perfil epidemiológico local, identificação dos problemas e planejamento das intervenções. Todos esses aspectos favorecem a aprendizagem significativa, servindo para uma formação profissional mais humanizada e contextualizada com a prática profissional, de acordo com as DCN e o SUS (MARIN et al., 2014; SANTOS; CAVALCANTE, 2019).

No entanto é necessário reconhecer que tais avanços, por si só, não garantem que o ensino seja integralmente pautado em uma nova lógica de atenção, uma vez que nos serviços de saúde ainda prevalece o atendimento à demanda e à queixa principal, aonde prevaleceu na realidade de saúde no Brasil, por muitas décadas, sem conseguir responder adequadamente às necessidades de saúde da população. Esse modelo hegemônico tem como características o atendimento individual, o fato de ser centrado na queixa e nos aspectos biológicos, a fragmentação do cuidado e o hospital como principal cenário de atenção. Também vale questionar a forma de inserção dos estudantes nos serviços, se vem ao encontro da prática dos profissionais que, muitas vezes, se encontram envolvidos em uma dinâmica complexa, com diversas atribuições, sem capacitação e habilidades para desenvolver tais funções (MARIN et al., 2014, GORDIANO, 2018; SANTOS; CAVALCANTE, 2019)

Assim, o percurso em prol de novas formas de agir e de pensar na formação em saúde e no cuidado situa-se entre as propostas de inovação do modelo de atenção tradicional ainda presente no cotidiano dos serviços, porém devendo ser incentivada e fortalecida nas IES, nos serviços e pelos seus respectivos gestores (MARIN et al., 2014, GORDIANO, 2018).

\section{0 estágio curricular supervisionado e sua intersecção com a formação da nutrição para a $\mathbf{A B}$.}

Dentro dos currículos de graduação em Nutrição no país, as DCN em seu Art. $7^{\circ}$, estabelecem que:

Interfaces da Educ., Paranaíba, v.11, n.31, p. 440 - 473, 2020 


\begin{abstract}
A formação do nutricionista deve garantir o desenvolvimento de estágios curriculares, sob a supervisão docente, e contando com a participação de nutricionistas dos locais credenciados. A carga horária mínima do estágio curricular supervisionado deverá atingir 20\% (vinte por cento) da carga horária total do Curso de Graduação em Nutrição proposto, com base no Parecer/Resolução específico da Câmara de Educação Superior do Conselho Nacional de Educação. (BRASIL, 2001)
\end{abstract}

Em Saúde Pública, os locais de estágio são aqueles onde o aluno pode desempenhar ações pertinentes às políticas públicas, majoritariamente as políticas de saúde e de alimentação e nutrição, desenvolvendo atividades relacionadas à atenção dietética. É o local onde seja possível a prática de diagnóstico nutricional individual e coletivo, o planejamento de ações de saúde, as atividades de educação em saúde e educação alimentar e nutricional, entre outras ações que possam se configurar dentro desse campo de práticas (BRASIL, 2001).

Para Gasparin (2003), o experimento do estágio se traduz como um caminho que os alunos têm que percorrer para que alcancem seus conhecimentos empíricos, através da prática social e histórica na qual estão inseridos, para adquirirem um conhecimento teórico-científico sólido. O estágio possibilita também estar ao lado de profissionais graduados, assim como conhecer as características do seu futuro local de trabalho; além disto, concebe uma oportunidade de autoconhecimento, permitindo ao estagiário testar seu comportamento frente aos problemas do cotidiano, bem como desenvolver competências relacionadas com a equipe de saúde e os colegas.

Neste estudo, os discentes de duas instituições ainda iriam iniciar o estágio no momento da produção dos dados dessa pesquisa. Deste modo, serão descritas aqui as suas expectativas para àquele momento:

GF 1: A gente vai vivenciar a parte prática no estágio, mas pelo que falam é uma experiência única, enriquecedora, onde a gente muda toda concepção da atuação do nutricionista na saúde pública”

GF 2: "Vamos fazer o estágio agora, vamos ter a experiência, os nossos campos de estágio não são tão bons mas vamos ver como vai ser, acho que é uma experiência única”. 
Já os discentes de uma Instituição de Ensino, que durante a produção dos dados tinham findado o Estágio Curricular, demonstraram ser uma experiência única e enriquecedora no processo de formação do nutricionista para atuar no contexto da $\mathrm{AB}$, conforme apresentado abaixo:

GF 3: "E ai a gente chega no estágio e a gente percebe que tudo aquilo que a gente estudou é necessário e que a gente consegue associar tudo. $E$ ai foi o que aconteceu, a gente pegou três milhões de politicas no estágio e precisou associar tudo. E ai a gente viu que a politica que no papel era morta, viva. E ai isso que é que a gente consegue perceber o que aconteceu na graduação toda. (..)."

GF 3: "Acho assim, da minha parte, meu maior crescimento nessa área, de vivenciar mesmo nessa parte da atenção básica foi no estágio (...)".

GF 3: "Sendo bem sincera, por mais que as professoras sejam muito engajadas, elas tentem, os assuntos, pelo menos com a minha experiência, eles ficam partidos, então a gente não consegue fazer essa união dos assuntos na teoria, como ela falou, a gente só conseguiu visualizar isso no estágio. Então até o oitavo período, que foi o último momento que a gente teve disciplina de saúde pública, as coisas ficaram muito partidas e saúde pública ficava sendo aquela disciplina de chata e punição. Não era uma disciplina que a gente se sentia agradável em estudar. To sendo extremamente sincera."

GF3: "O estágio foi o divisor ne? Antes do estágio eu não queria ouvir falar em saúde pública de jeito nenhum, era uma coisa que eu tinha que realmente fazer, que era obrigada, que não dava para fugir, depois do estágio não, essa concepção já foi mudando um pouco mais. Então a gente vê que realmente o diferencial é a pratica que o estágio curricular proporciona. Sem essa pratica, ninguém vai para saúde pública. Só quem realmente já nasce com aquele dom maravilhoso. Rs”

As falas acima evidenciam o estágio supervisionado como espaço para desenvolvimento das competências dos profissionais, assim como as competências e habilidades específicas para os discentes de nutrição. Benito et al. (2012), pondera que, a partir do conteúdo teórico contraído em toda a graduação, o acadêmico, com o estágio supervisionado, desenvolve uma visão diferenciada do campo de trabalho, podendo ampliar atividades inerentes ao exercício profissional.

Desta forma, podemos entender que prática é transformadora, tanto para o acadêmico, quanto para o local do trabalho onde a ação vai ser desenvolvida, pois, ao efetuar uma ação, o aluno se baseia em elementos teóricos atuais que cooperam para modificar e inovar o espaço dos serviços de saúde. Portanto, o acadêmico aumenta competências de acordo com a individualidade, o coletivo e a organização do serviço no qual está inserido. 
Espera-se que, com o estágio curricular supervisionado, as competências profissionais sejam promovidas, fortalecidas e expandidas, significando a maneira mais eficiente e duradoura de adquirir conhecimento, habilidade e atitude (COLLISELLI et al., 2009 citado por BENITO et al., 2012).

É no estágio que o aluno vê a importância de planejar as suas ações, assim como aprende a lidar com a flexibilidade perante as decisões tomadas. No campo de prática, o estagiário tem a possibilidade de se tornar um sujeito provocador de mudanças ao adquirir uma prática social, inserida no contexto de um sistema de saúde universal, igualitário, integral, de qualidade e fundamentado nos princípios de cidadania, buscando a consolidação do SUS (BENITO et al., 2012).

Diante do que já foi discutido acerca do processo de formação para o nutricionista na $\mathrm{AB}$, sendo enfatizada a importância do trabalho interdisciplinar, com vivências nas redes de atenção à saúde através de diversos métodos de ensino-aprendizagem, apontamos também o estágio integrado em saúde, como uma estratégia fortalecedora do estágio supervisionado em saúde pública, com o intuído de avançarmos ainda mais na aprendizagem do acadêmico de nutrição no contexto da $\mathrm{AB}$, fortalecendo a interdisciplinarida e a integralidade.

Uchôa (2018), em seu estudo, que teve como objetivo analisar, através da perspectiva discente, as contribuições do Estágio Integrado em Saúde (EIS), uma proposta de educação interprofissional, de uma instituição pública de Maceió AL, concluiu que na percepção dos discentes, a EIS apresenta-se como um cenário favorável e potencializador para a importância do entendimento do trabalho em equipe para as práticas integrativas em saúde.

O EIS se demudou em uma estratégia pedagógica para os cursos da saúde, incluindo a nutrição, amparando na produção de ferramenta teóricosmetodológicas coesas e capazes de promover a gestão e na produção dos cuidados em saúde na lógica do SUS, gerando mudanças no perfil de formação em saúde e procurando auxiliar o rompimento do modelo biologicista, prescritivo, curativo, com baixo poder de resolutividade dos serviços de saúde por parte dos profissionais (AQUILINO, 2016). 
As Unidades Básicas de Saúde apresentam-se como cenários de prática para o estágio curricular em Nutrição em Saúde Pública, sob a supervisão de um nutricionista da rede que pode ser vinculado ao NASF-AB ou não, sendo esses os espaços onde se encontra boa parte dos nutricionistas que exercem suas atividades na rede. Na prática, entre os cursos de Nutrição no país, a atenção básica tem sido um dos espaços mais privilegiados onde o estágio supervisionado em Nutrição Social pode ser desenvolvido (AQUILINO, 2016).

Alves (2018) destaca ainda que o estágio supervisionado em Nutrição em Saúde Pública, enquanto desenvolvido na atenção básica na rede de saúde, pode ser considerado um período propício para a aprendizagem do acadêmico de Nutrição, ponderando o desenvolvimento de competências e habilidades, além de permitir a visualização do campo de atuação do profissional de Nutrição como forma de desenvolvimento de uma identidade profissional para atuar na área.

\section{Considerações finais}

Os discentes de nutrição apresentaram a metodologia tradicional como o método de ensino-aprendizagem mais utilizado no processo de formação para a $\mathrm{AB}$, podendo ser um dos fatores que limitaram a compreensão e atração destes discentes acerca da temática estudada, nos fazendo refletir acerca da importância de inserção das novas tendências pedagógicas, como as metodologias ativas de aprendizagem, na estrutura dos currículos.

Outro achado apontado pelos discentes foi referente aos conteúdos teóricos de nutrição acerca da $\mathrm{AB}$ que se sobrepuseram em detrimento da prática, cujas atividades práticas que ocorriam eram de maneira pontual e fragmentada, que não permitiram entender os reais objetivos e houve dificuldade em relacionar os conteúdos teóricos ministrados em sala de aula.

Entretanto, colocam o Estagio Curricular Supervisionado (ECS) como sendo espaços privilegiado para a formação, bem como uma experiência crucial, única e enriquecedora no processo de ensino-aprendizagem do nutricionista para atuar no contexto da AB.

Considera-se pertinente adequações no processo de formação dos nutricionistas, envolvendo a mudança de práticas pedagógicas tradicionais Interfaces da Educ., Paranaíba, v.11, n.31, p. 440 - 473, 2020 
para praticas que englobem os novos métodos de ensino-aprendizagem, a diversidade dos cenários de pratica, sendo pertinentes estas práticas desde o início, pois assim fomentam uma aprendizagem na perspectiva crítica e reflexiva, conforme orientas as Diretrizes Curriculares do curso

Além disso, o fortalecimento da integração ensino-serviço para que as dificuldades entre a universidade e a complexidade da realidade do serviço sejam compreendidas, avançando assim no fortalecimento da assistência à saúde e no processo de formação.

Os resultados desta pesquisa sugerem, também, a necessidade de Educação Permanente em Saúde como prática para os docentes com o intuito de incentivar a produção de conhecimentos, teóricos e práticos, no cotidiano de trabalho das instituições de ensino, configurando-se como uma estratégia em potencial para o aperfeiçoamento da prática profissional

Novas pesquisas, bem como o compartilhamento de experiências exitosas, que abordem a formação do nutricionista para atuar no contexto da saúde pública e/ou $\mathrm{AB}$, com base nas análises das DCN e de Projetos Pedagógicos dos Cursos de Graduação em Nutrição no Brasil, devem ser incentivadas, por possibilitar o avanço das discussões da atuação do nutricionista no âmbito do SUS e atenção básica, por fomentar a formação dos discentes e futuros nutricionistas.

Nesse sentido, por considerar oportuno e emergente a promoção de espaços que favoreçam a problematização e/ou discussão acerca da formação da nutrição em saúde pública e/ou AB dos docentes e instituições de ensino, e por acreditar que os ambientes virtuais de aprendizagem facilitam o acesso a aprendizagem de forma acessivel e interativa as discussões, foram elaborados, quatro produtos educacionais, sendo um MOOC ("Massive Open Online Courses") intitulado: "Repensando a formação da nutrição acerca da Atenção Básica", desenvolvido através da plataforma Moodle ("Modular Object-Oriented Dynamic Learning Environment") e três vídeos que compõem o conteúdo programático do referido MOOC, voltados para os docentes, preceptores e coordenadores do curso de nutrição da área de nutrição e saúde pública e/ou atenção básica, mas, principalmente, para os docentes das Instituições de Ensino que participaram desta pesquisa, como estratégia de Interfaces da Educ., Paranaíba, v.11, n.31, p. 440 - 473, 2020 
retorno da pesquisa as instituições sendo apontada também como uma das implicações práticas e social positiva da pesquisa. Vale mencionar ainda, que o referido MOOC já encontra-se de acesso pelos docentes das instituições e em breve será publicado nas plataformas educacionais para acessos dos demais docentes e preceptores de outras instituições, sendo estes considerados potenciais implicações sociais e práticas do estudo.

Com relação as limitações deste estudo podemos citar a dificuldade dos discentes de aprofundar a discussões de algumas categorias abordados na pesquisa, principalmente na categoria 4, que faz menção ao estágio supervisionado e sua intersecção com a formação da nutrição para a AB, pois em duas universidades os alunos não tinham iniciado e/ou concluído o estágio curricular supervisionado no período da produção dos dados, o que pode estar relacionado com uma menor compreensão acerca da na atenção básica bem como sobre o processo de ensino-aprendizagem que o estágio curricular proporciona na área, sendo colocados as expectativas e/ou a importância desses momentos para a formação para a atenção básica.

\section{Referências}

AGUIAR, C. B; COSTA, N.M.S.C. Formação e atuação de nutricionistas dos Núcleos de Apoio à Saúde da Família. Rev. Nutr., Campinas, v.28, n.2, p.207216, mar./abr., 2015. Disponivel em:< http:/ / www.scielo.br/scielo.php?pid=S1415-

52732015000200207\&script=sci_abstract\&tlng=pt>. Acesso em: 30 dez. 2018.

ALVES, J. E. D. As diferentes velocidades do envelhecimento populacional. Ecodebate, 2017. Disponivel em: https:/ /www.ecodebate.com.br/2017/12/01/as-diferentes-velocidades-doenvelhecimento-populacional-artigo-de-jose-eustaquio-diniz-alves/.

ALMEIDA FILHO, N. Transdisciplinaridade e o paradigma pós-disciplinar na saúde. Saúde e Sociedade, São Paulo, v. 14, n. 3, p. 30-50, 2005. 
AQUILINO, G.M.A. Estágio Integrado e a Formação em Saúde: a experiência em uma Unidade Docente Assistencial. Maceió- AL, 2016. Dissertação (Mestrado Profissional de Pesquisa em Saúde) Centro Universitário Cesmac, Maceió-AL, 2016.

ARAÚJO, F. G. Tendência da prevalência de sobrepeso, obesidade, diabetes e hipertensão em mulheres brasileiras em idade reprodutiva, Vigitel 2008-2015 [manuscrito] / Fernanda Gontijo Araújo. - 2018. 109 f. Dissertação (Mestrado) - Universidade Federal de Minas Gerais, Escola de Enfermagem. Disponivel em: http://www.enf.ufmg.br/pos/defesas/937M.PDF. Acesso em; 14 de abril de 2019.

ARAÚJO, J.D. Polarização Epidemiológica no Brasil. Epidemiol. Serv. Saúde, Brasília, v.21, n.4, p.533-538, out - dez 2012. Disponivel em: <http://scielo.iec.gov.br/pdf/ess/v21n4/v21n4a02.pdf>. Acesso em 02 jan. 2019.

BATISTA FILHO, M.; RISSIN, A. A Transição Nutricional no Brasil: tendências regionais e temporais. Caderno de Saúde Pública, 19 (Sup. 1): S181-S191, 2003, Rio de Janeiro, v. 1, n. 19, p. 181-191, jan. 2003. Disponivel em: < http:/ / www.scielo.br/scielo.php?pid=S0102-

311X2003000700019\&script $=$ sci_abstract\&tlng=pt>. Acesso em: 04 jan.2019.

BRASIL. Ministério da Saúde. Aprova a Política Nacional de Atenção Básica, estabelecendo a revisão de diretrizes para a organização da Atenção Básica, no âmbito do Sistema Único de Saúde (SUS). Portaria n. 2.436, de 21 de setembro de 2017.Brasília, DF: Ministério da Saúde, 2017b. Disponivel em:<https://www.nescon.medicina.ufmg.br/biblioteca/registro/Portaria_no 2_436_de_21_de_se tembro_de_2017/295>. Acesso em: 17 jun. 2018.

BRASIL. Conselho Nacional de Educação, Câmara de Educação Superior. Institui Diretrizes Curriculares Nacionais do Curso de Graduação em Nutrição. Resolução n. 5, de 7 de novembro de 2001. Diário Oficial da República Federativa do Brasil, Brasília, DF, 9 nov. 2001a. Disponível em: Interfaces da Educ., Paranaíba, v.11, n.31, p. 440 - 473, 2020 
<http://portal.mec.gov.br/cne/arquivos/pdf/CES05.pdf>. Acesso em: 24 jan. 2019.

BARDIN, L. Análise de conteúdo. São Paulo: Edições 70. 2011.

BOGANHA, A.S. Introdução de metodologias ativas no ensino de nutrição clínica em um curso de técnico em nutrição e dietética. Dissertação (Pontifica Universidade Católica de São Paulo. Faculdade de Ciências Medicas e da Saúde, 2016.

BERBEL, N. A. N. As metodologias ativas e a promoção da autonomia de estudantes. Semina: Ciências Sociais e Humanas, Londrina, v. 32, n. 1, p. 2540, jan./jun. 2011.

BENITO, G.A.V. et. Al. Desenvolvimento de competências gerais durante o estágio supervisionado. Rev Bras Enferm, v. 65, n. 1, p. 172-178, 2012. Disponivel em: http:/ / www.scielo.br/scielo.php?script=sci_arttext\&pid=S003471672012000100025 . Acesso em: 15 mar.2019.

BORGES, T. S.; ALENCAR, G. Metodologias ativas na promoção da formação crítica do estudante: o uso das metodologias ativas como recurso didático na formação crítica do estudante do ensino superior. Cairu em Revista, Salvador, ano 3, n. 4, p. 119-143, jul./ ago. 2014.

CUNHA, D.; RODRIGUES, V.B. Vivência do residente em nutrição da RMAB no processo de trabalho do NASF na Região de saúde leste do Distrito Federal. Tempus, actas de saúde colet., Brasília, v.10, n.4, p. 289-295, dez, 2016. Disponivel em: http://www.tempusactas.unb.br/index.php/tempus/article/view/2288>. Acesso: 23 jul.2018.

CHRISTENSEN, C.; HORN, M.; STAKER, H. Ensino Híbrido: uma Inovação Disruptiva?. Uma introdução à teoria dos híbridos. Maio de 2013. Disponível em: https: / /www.pucpr.br/wp- 
content/uploads/2017/10/ensinohibrido_uma-inovacao-disr uptiva.pdf Acesso em: 02 jul. 2018

ESCOBAR, S. J. M. Ensino-aprendizagem na graduação em nutrição. Congresso Nacional de Educação EDUCERE. Pontifica Universidade Católica do Paraná. Curitiba, 2013.

FUJITA, J. A. L. et al. Uso da metodologia da problematização com o Arco de Maguerez no ensino sobre brinquedo terapêutico. Rev. Port. de Educação, Braga , v. 29, n. 1, p. 229-258, jun. 2016 . Disponivel em <http://www.scielo.mec.pt/scielo.php?script=sci_arttext\&pid=S0871918720 $16000100011 \& \operatorname{lng}=$ pt\&nrm=iso $>$. acesso em 27 de março de 2018.

FREIRE, P. Educação como prática da liberdade. Rio de Janeiro: Paz e Terra, 1994.

FREIRE, P. Pedagogia do oprimido. Rio de Janeiro: Paz e Terra, 31. ed. 184 p, 2001.

GARCIA, M. A. A. et al. A interdisciplinaridade necessária para a formação médica. Revista Brasileira de Educação Médica, Rio de Janeiro, v. 31, n. 2, p. 147-155, 2007.

GORDIANO, E.A. Pbl na formação de acadêmicos de nutrição: uma revisão integrativa - 2008 a 2018. Monografia (Especialista em Ensino Médico). Programa de Pós-Graduação em Ensino Médico, Setor de Ciências da Saúde da Universidade Federal do Paraná. Curitiba, 2018.

GASPARIN, JL. Uma Didática para a Pedagogia Histórico-Crítica. $2^{\mathrm{a}}$ ed. Campinas, SP: Autores Associados; 2003.

JUNQUEIRA, T. S; COTTA, R.M.M. Matriz de ações de alimentação e nutrição na Atenção Básica de Saúde: referencial para a formação do nutricionista no contexto da educação por competências. Ciênc. Saúde Coletiva, [s.1.], v. 19, n. 5, p. 14591474, maio 2014. Disponivel em:< 
http:/ / www.scielo.br/scielo.php?pid=S1413-

$81232014000501459 \&$ script=sci_abstract\&tlng=pt>. Acesso em: 27 fev.2019.

LIMA, A.P. et al. Atenção domiciliar em saúde bucal: experiência de integração ensino-serviço-comunidade em centro de saúde da família. SANARE, Sobral V.18 n.01 ,p.90-97, Jan./Jun. - 2019. Disponivel em: https://sanare.emnuvens.com.br/sanare/article/viewFile/1309/690.

Acesso em: 28 dez.2019.

MENEZES, M. G; SANTIAGO, M. E. Contribuição do pensamento de Paulo Freire para o paradigma curricular crítico-emancipatório. Pro-Posições, Campinas, v. 25, n. 3, p. 45-62, dez. 2014. Disponivel em: <http://www.scielo.br/pdf/pp/v25n3/v25n3a03.pdf>. Acesso em: 23 fev. 2019.

MALTA, D.C. et al. Doenças crônicas não transmissiveis e a utilização de serviços de saúde: análise da Pesquisa Nacional de Saúde no Brasil. 1. Rev Saúde Publica. 2017;51 Supl 1:4s. Disponivel em: http:/ /www.scielo.br/pdf/rsp/v51s1/pt_0034-8910-rsp-S151887872017051000090.pdf. Acesso em: 14 de abril de 2019.

MAIS, L. A. et al. Formação de hábitos alimentares e promoção da saúde e nutrição: o papel do nutricionista nos núcleos de apoio à saúde da família NASF. Ciência \& Saúde Coletiva APS, São Paulo, v. 2, n. 18, p. 248-255, abr. 2015. https://periodicos.ufjf.br/index.php/aps/article/view/15484. Acesso em: 28 jan.2019.

MARIN, M.J.S., et al. A integração ensino-serviço na formação de enfermeiros e médicos: a experiência da FAMEMA. Ciência \& Saúde Coletiva, v.19, n.3, p. 967-974, 2014. Disponivel em: http://www.scielo.br/scielo.php?pid=S1413$81232014000300967 \&$ script=sci_abstract\&tlng=pt . Acesso em: 27 dez. 2019.

MENDES, C. V. A utilização das tecnologias digitais da informação e comunicação no ensino técnico em enfermagem: um estudo da prática docente 
/ Cynthia Vieira Mendes. - Itajubá: UNIFEI, 2016. Disponivel em: <https://repositorio.unifei.edu.br/xmlui/bitstream/handle/123456789/466 /disserta cao_mendes_2016.pdf?sequence $=1$ \&isAllowed $=>$. Acesso em: 02 jul. 2018.

MITCHELL, S.; SHAW, D. The worldwide epidemic of female obesity. Best Practice \& Research. Clinical Obstetrics \& Gynaecology, Netherlands, v.29, n.3, p. 289-299, 2015. Disponível em: Acesso em: 17 jan. 2018.

MITRE, S. M. I. et al. Metodologias ativas de ensinoaprendizagem na formação profissional em saúde: debates atuais. Ciência e Saúde Coletiva, Rio de Janeiro, v. 13, s. 2, p. 2133-2144, 2008.

MENDES, F. R. P. et al. Social Representations of nursing students about hospital assistance and primary health care. Rev. Bras. Enferm., Brasília, v. 69, n. 2, p. 321-328, apr. 2016.

MINAYO, M.C.S. O desafio do conhecimento: pesquisa qualitativa em saúde. 14. ed., São Paulo: Hucitec, 2014. 407 p.

MORAN, J. M. Mudando a educação com metodologias ativas . In: SOUZA, C. A.;MORALES, O. E. T. (Org.). Convergências midiáticas, educação e cidadania: aproximações jovens, v. 2. Ponta Grossa: Foca FotoPROEX/UEPG, 2015. (Coleção Mídias Contemporâneas). Disponivel em: < http://www2.eca.usp.br/moran/wp-content/uploads/2013/12/ mudando moran.pdf > .Acesso em: 2 jul. 2018.

OLIVEIRA, E.S. G. et al. Formação docente para o uso das tecnologias digitais: novos saberes do professor . Revista do Seminário Mídias \&Educação. V.1, 2015.

Disponivel em:

<http://cp2.g12.br/ojs/index.php/midiaseeducacao/article/view/505 $>$.Acessoem: 02 Jul. 2018.

INTO, L.L.S.; FORMIGLI, V.L.A.; RÊGO, R.C.F.A dor e a delícia de aprender com o SUS: integração ensino serviço na percepção dos internos em medicina social. Rev Baiana Saúde Pública, v.3, p.115-133. 2007. 
PINHEIRO, A.R.O et. al. Percepção de professores e estudantes em relação ao perfil de formação do nutricionista em saúde pública. Rev. Nutr., Campinas, v. 25, n.5, p.631-643, set./out., 2012. Disponivel em: http://www.scielo.br/pdf/rn/v30n6/1415-5273-rn-30-6-0835.pdf . Acesso em: 20 abri 2019.

RECINE, E. et al. A formação em saúde pública nos cursos de graduação de nutrição no Brasil. Rev. Nutr., Campinas, v.25, n.1, p.21-33, jan.- fev., 2012. Disponivel em:< http://www.scielo.br/scielo.php?pid=S1415$52732012000100003 \&$ script $=$ sci_abstract\&tlng=pt $>$. Acesso em: 18 abril 2019.

SOBRAL, F.R; CAMPOS, C.J.G. Utilização de metodologia ativa no ensino e assistência de enfermagem na produção nacional: revisão integrativa. Rev Esc Enferm USP 2012; 46(1):208-18.

SANTOS, J. C.R. Metodologias ativas e interdisciplinaridade na formação do nutricionista. Semina: Ciências Sociais e Humanas, Londrina, v. 38, n. 1, p. 117-128, jan./jun. $2017 . \quad$ Disponivel: http://www.uel.br/revistas/uel/index.php/seminasoc/article/view/28205. Acesso em: 25 junho. 2019.

SANTOS, A. C. A inserção do nutricionista na estratégia da saúde da família: o olhar de diferentes trabalhadores da saúde. Fam. Saúde Desenv., Curitiba, v. 3, n. 7, p. 257-265, set. 2005. Disponivel em: < https://revistas.ufpr.br/refased/article/view/8033>. Acesso em: 04 fev.2019.

SANTOS, I.C.N.; CAVALCANTE, M.P. A integração do ensino, serviço e comunidade nos serviços de saúde do vi e vii distritos sanitários. GEPNEWS, Maceió, a.3, v.2, n.2, p.161-168, abr./jun. 2019. Disponivel em: http://www.seer.ufal.br/index.php/gepnews/article/view/7894. Acesso em: 27 dez.2019. 
SOUZA, E.B. Transição nutricional no Brasil: análise dos principais fatores. Cadernos UniFOA. Volta Redonda, Ano V, n. 13, agosto 2010. Disponível em: http:/ / revistas.unifoa.edu.br/index.php/cadernos/article/view/1025/895. Acesso em: 14 de abril 2019.

SOUZA, C.H.M.; CALABAIDE, C. ERNESTO, T.S. REFLECTIONS ON ACTIVE METHODOLOGIES X TEACHING PRACTICE. Interdisciplinary Scientific Journal v.5, n.4, p.212-222, Oct-Dec, 2018. Disponivel em: http://revista.srvroot.com/linkscienceplace/index.php/linkscienceplace/art icle/view/582/312. Acesso em: 27 dez. 2019.

SCHOTT, M. Articulação ensino-serviço: estratégia para formação e educação permanente em saúde. REFACS (online), Minas Gerais, v. 6, n. 2, abr-jun. 2018.

Disponivel em: <http://www.redalyc.org/articulo.oa?id=497955513017>. Acesso em: 8 ago. 2018.

TEIXEIRA, J.A; SILVA, B.E.M. A importância da intervenção do nutricionista na rede pública de saúde. Revista Perquirere. Patos de Minas, n14, v.1, p.119127, jan./abril. 2017. Disponivel em:< http:/ / perquirere.unipam.edu.br/documents / 23456/1739550/A+import\%C 3\%A2ncia+da+interven $\% \mathrm{C} 3 \% \mathrm{~A} 7 \% \mathrm{C} 3 \% \mathrm{~A} 3 \mathrm{o}+\mathrm{do}+$ nutricionista.pdf $>$. Acesso em: 28 de jan.2019.

UCHÔA, P. A. Estágio integrado em saúde e aprendizagem interprofissional: Percepção dos discentes. Dissertação (Mestrado Profissional em Ensino na Saúde) Universidade federal de Alagoas. Faculdade de medicina, 2018.

VASCONCELOS, F.A.G. O nutricionista no Brasil: uma análise histórica. Rev Nutr. 2002; v.15, n.2, p.127-38, 2002. Disponivel em: < http:/ / www.scielo.br/scielo.php?pid=s 1415-

$52732002000200001 \&$ script $=$ sci_abstract\&tlng=pt>. Acesso em: 25 de nov. 2018 
WORLD HEALTH ORGANIZATION (WHO). Obesity: preventing and managing the global epidemic. Report of a World Health Organization Consultation. Geneva: World Health Organization, 2017. Disponivel em: < whqlibdoc.who.int/trs/WHO_TRS_894.pdf>. Acesso em: 04 fev.2019.

YPIRANGA, L.; GIL, M.F. Formação profissional do nutricionista: por que mudar? In: CUNHA, D.T.O., YPIRANGA, L., GIL, M.F. (Org.). II Seminário Nacional sobre o ensino de nutrição. Goiânia: FEBRAN, 1989. p. 2036.Available from: < http://www.scielo.br/pdf/reben/v69n2/0034-7167reben-69-02-0343.pdf>. Access: 2018 jun. 28. 